\title{
EVALUATION OF CORNER JOINT STRENGTH OF COMPOSITE PANELS BONDED WITH MODIFIED STARCH
}

\author{
Onur Ulker, Mercan Haddad Derafshi \\ 1UNiversity OF KiRIKKALE \\ TURKEY \\ 2Indiana University of Pennsylvania \\ USA
}

(Received December 20i9)

\begin{abstract}
The objective of this research was to evaluate the strength of corner joints of box shaped furniture made from eastern red cedar (Juniperus virginiana L.) and corn starch binder southern sample. Various types of corner joint techniques were evaluated (glued, glued and screwed, and glued with dowel corners). Eastern redcedar particle samples with corn starch and glutaraldehyde were used. Overlaid and non-overlaid particleboards along with sandwich panels were used at "L" type corner joints. Tension and compression strength moment values were measured. Particleboard panel joint mounted with dowel resulted in the highest tension strength moment values followed by the specimens having a sandwich-type configuration combined with a dowel. Particleboard and overlaid sandwich-type panels glued with polyvinyl acetate (PVAc) had the lowest strength values. It appears that composite panels manufactured with modified starch have the potential to be used for corner joints.
\end{abstract}

KEYWORDS: Eastern red cedar, particleboard, sandwich panel, overlay, diagonal tensile strength, diagonal compression strength.

\section{INTRODUCTION}

Particleboard is one of the most common manufactured wood-based composite panels used in furniture and cabinet production. Most of the cabinet and furniture panels are exposed to compression and tension forces during their lifespan. Depending on the magnitude of such forces deformation such as breaking, separation bending, and layering could take place in the cabinet or furniture units. Therefore, it is important to consider such forces so that raw material and finished products could be designed with an acceptable property (Eckelman and Rabiej 1985, 
Smardzewski 1993, Erdil et al. 2005, Zhang et al. 2005, Podlena and Borůvka 2016, Záborský et al. 2017a,b). Wood and wood-based materials are important components of furniture design and furniture construction design. The advance knowledge of the behavior of such materials regarding physical and mechanical forces applied to furniture provides technical, aesthetic, and economic benefits to the designer, manufacturer, and eventually users (Eckelman 1979, Kasal et al. 2016, Imirzi et al. 2016, Cinar et al. 2019, Ulker and Burdurlu 2016).

The type of adhesive and corner joint types plays a significant role in the overall joint strength of furniture units (Fatery and Williamson 1997, Rajak and Eckelman 1993). It is suggested that the most effective method of building furniture and elements of wood material is by bonding the joints. Furthermore, the majority of the openings in the joints are caused by technological mistakes that occur during the gluing processes; the heterogeneous distribution of the glue on the surface is negatively affected by cohesion (Smardzevski 2002, Prekrat et al. 2004, Efe and Imirzi 2008, Ulker 2018). Simek et al. 2010 examined the effect of end distance of cam fasteners and the number of dowels on bending moment capacity of $L$ type furniture corner joints. Their results indicated a $60 \mathrm{~mm}$ end distance gave as the highest moment capacity of cam connectors; two cam fasteners with the addition of 2, 3 and 4 unglued dowels were superior in terms of moment capacity.

In another study, the physical and mechanical properties of corner joints were evaluated from the perspective of tensile and compression strength. The highest and lowest tensile strength found in melamine-composite panels were $1192 \mathrm{~N} \cdot \mathrm{mm}^{-2}$ and $929 \mathrm{~N} \cdot \mathrm{mm}^{-2}$, respectively. The authors concluded that, adhesives and material type influence corner joint strength (Atar et al. 2009). Bending capacities of plywood frames were assessed by Jensen and colleagues. Modules of rupture (MOR) for compression and tensile moment was $30 \mathrm{MPa}$ for the small cross-sections and $22 \mathrm{MPa}$ for the large cross-sections (Jensen et al. 2002). The effect of the number of joints in frames from OSB (oriented strand board) and type of adhesive on the diagonal tensile strength of the frame was determined by Ozkaya et al. (2010). The highest diagonal tensile strength of the frame was $0.117 \mathrm{~N} \cdot \mathrm{mm}^{-2}$ with single dovetail joint bonded with PVAc. The lowest diagonal tensile strength of the frame was single and double joints without adhesive (Ozkaya et al. 2010).

Altinok (2009) investigated the durability of three corner joints with melamine overlaid particleboards. Corner joint types were PVAc spline joint, PVAc dowel joint, spline-dowel polymarine, and PVAc combinations all of which, are used in furniture constructions. The maximum tension strength observed in PVAc combination and maximum compression strength found in polymarine combination was $27.26 \mathrm{~N} \cdot \mathrm{mm}^{-2}$ and $8.66 \mathrm{~N} \cdot \mathrm{mm}^{-2}$, respectively. Altun et al. (2010) analyzed the bending moment capacity of miter frame corner joints. They used $\mathrm{MDF}$ as the frame material and assessed compression and tensile loads on corner joints. Results revealed that the highest bending moment capacity at diagonal tensile stress (46.09 N.m) was in cyanoacrylate glued corners. Furthermore, the highest diagonal compression stress values were found in PVAc glued corner joints (72.04 N.m).

Combination of material type with corner joint type is also important in evaluating furniture (Efe et al. 2014, Koreny et al. 2013, Podlena et al. 2017). "L" type furniture made from a combination of wood-based and high resistance materials are listed from highest strength to lowest: Okume plywood, fiberboard (MDF), laminated fiberboard, particleboard (PB), laminated particleboard and oriented strand board (OSB). The physical and mechanical properties of the above-mentioned samples have been well investigated as evident in the substantial amount of data found in the literature (Eckelman 2003, Kasal et al. 2006, Vassiliou and Barboutis 2009, Smardzewski 2002, Yerlikaya 2014, Küçüktüvek et al. 2017). Furthermore, Yerlikaya and Aktas (2012) investigated the load carrying capacity of corner joints in furniture and found that the 
most robust joining was the combination of dowel, minifix, and fabric. Whereas, the weakest joining was seen in dowel corner joints. Eastern redcedar (Juniperus virginiana) has a wide habitat in the State of Oklahoma and in the surrounding States. It is estimated that there is more than 4.5 million hectares of eastern redcedar and this number is projected to increase in the future. Large trees are popular in the furniture industry on the contrary, eastern redcedar is underutilized due to its small size. Although eastern redcedar is generally not considered to be an important commercial species, its wood is highly valued for its durability and workability and it is widely habitant in the State of Oklahoma.

To the best of our knowledge, there is little or no information on the corner joint properties of eastern red cedar $\mathrm{PB}$, overlaid eastern redcedar $\mathrm{PB}$, sandwiched panel $\mathrm{PB}$, and overlaid sandwiched eastern redcedar panels.

\section{MATERIALS AND METHODS}

\section{Sample preparation}

Eastern red cedar (Juniperus virginiana L.) particles were obtained from a local sawmill in Oklahoma City, USA. The particles contained both hardwood and softwood fractions. Particles were dried to $2-3 \%$ moisture content in a laboratory type oven with a $1.0 \mathrm{~m}^{3}$ volume at $67 \pm 2^{\circ} \mathrm{C}$ for 72 hours. Dried particles were classified into two fractions, on a 1 and $3 \mathrm{~mm}$ screen, namely fine and coarse, respectively. After screening, 2\% urea formaldehyde (UF) and 13\% corn starch glutaraldehyde were blended with particles. Experimental panels were compressed at a temperature of $180 \pm 2^{\circ} \mathrm{C}$ and a pressure of $5.17 \mathrm{MPa}$ for $5 \mathrm{~min}$. All panels were pressed to a nominal thickness of $14 \mathrm{~mm}$, and their target density was $0.70 \mathrm{~g} \cdot \mathrm{cm}^{-3}$. Panels were prepared with the dimensions of $500 \times 500 \times 14 \mathrm{~mm}$ (length $\mathrm{x}$ width $\mathrm{x}$ depth). Screws were obtained from a local dealer in Stillwater, Oklahoma. For fixing "L" type corner joints, wooden dowels were supplied from a local shop in Stillwater, Oklahoma USA. A dowel of $8 \mathrm{~mm}$ in diameter and $30 \mathrm{~mm}$ in length that was prepared from yellow poplar was used (Fig. 1.)

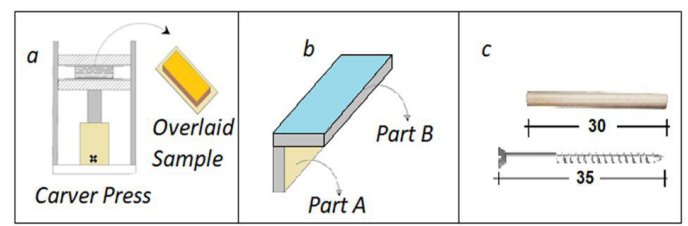

Fig. 1: a) Panel overlaying setup, b) "L" type construction, c) wood dowel and screw.

Polyvinyl acetate (PVAc) adhesive, a widely used glue in the furniture industry was supplied from local markets and was used in the test specimens. A total of twenty (ten for each composite type) particleboards were overlaid with a melamine-based decorative paper $\left(00165 \mathrm{~g}^{\mathrm{cm}} \mathrm{cm}^{-2}\right)$ with the dimensions of $200 \times 100 \mathrm{~mm}$. Particleboard samples were overlaid for the duration of 50 seconds at the carver press with a temperature of $165^{\circ} \mathrm{C} \pm 5^{\circ} \mathrm{C}$ and pressure of $2.3 \mathrm{MPa}$. Prior to any surface measurements, samples were conditioned in a chamber with a temperature and a relative humidity of $20^{\circ} \mathrm{C}$ and $65 \%$, respectively, until they reached to equilibrium moisture content. Overlaying process of particleboards, sandwiched panels, and the prepared test sample are depicted in Fig. 1. Each experimental sample consists of two parts; part A is $20 \times 8.6 \times 1.4 \mathrm{~cm}$ (length $\mathrm{x}$ width $\mathrm{x}$ depth), and part B is $200 \times 100 \times 14 \mathrm{~mm}$ (length $\mathrm{x}$ width $\mathrm{x}$ depth). 
Compression and tensile strength tests were carried out with one-ton Comten brand series 95, Universal testing machine. All the tests were carried out with $2 \mathrm{~mm} \cdot \mathrm{min}^{-1}$ static loads in the vertical direction. The torque arm distance was calculated using $\mathrm{Ly}=0.0558 \mathrm{~m}$ for compression and $L x=0.06081 \mathrm{~m}$ for tensile using the right triangular connection. Corner "A" illustrated in Fig. 2a is the diagonal pressure experiment, the moment carried under test loads, and the moments carried by each sample under diagonal tensile and compressive loads. The tensile, compressive loads, dimensions of dowels, and screws inserted in the samples are illustrated in Fig. 2.

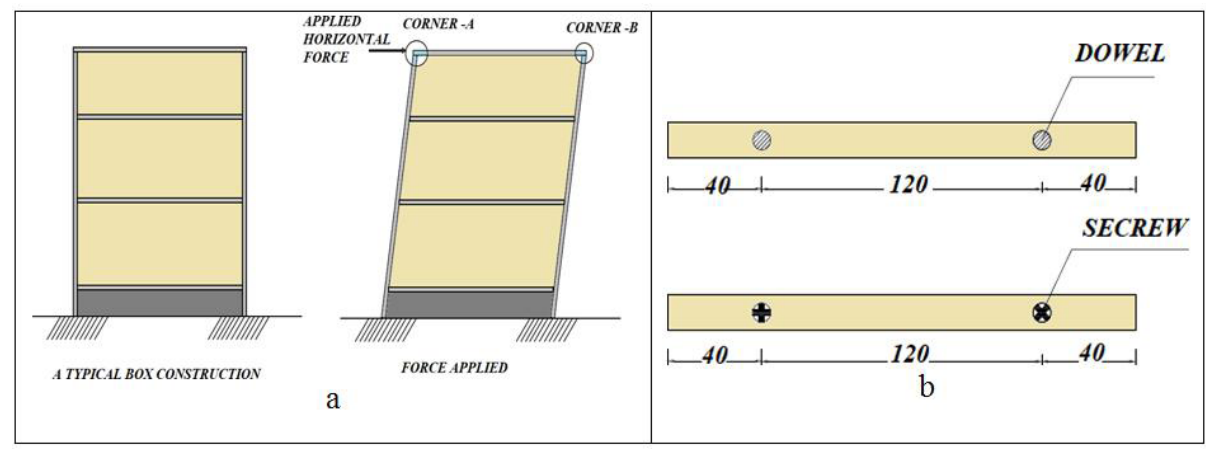

Fig. 2: a) Box construction of cupboard, b) dimensions of inserted dowel and screw sizes.

In the diagonal tensile test, the moment $(M d t)$ inserted to corner " $\mathrm{A}$ " is calculated by the following equation (Fig. 3a):

$$
\mathrm{M}_{\mathrm{dt}}=0.5 \mathrm{~F}_{\max T n} \times L_{x} \quad(\mathrm{~N} . \mathrm{m})
$$

where: $\quad \mathrm{M}-$ moment of inertia $(\mathrm{N} \cdot \mathrm{m})$,

$\mathrm{F}_{\max T n}$ - maximum force at the moment of displacement $(\mathrm{N})$,

$L x$ - torque distance $(60.81 \mathrm{~mm})$.

In the diagonal compression test, the moment (Mdp) inserted to corner "B" is calculated by the following equation (see Fig. 3b):

$$
\mathrm{Mdp}=\mathrm{F}_{\max } \mathrm{P}_{\mathrm{r}} \times \mathrm{L}_{\mathrm{y}} \quad \text { (N.m) }
$$

where: Mdp - torque transmitted under pressure load (N.m),

$\mathrm{F}_{\max } \mathrm{P}_{\mathrm{r}}-$ maximum force at retraction $(\mathrm{N})$,

$\mathrm{L}_{\mathrm{y}}$ - moment line $(55.86 \mathrm{~mm})$. 

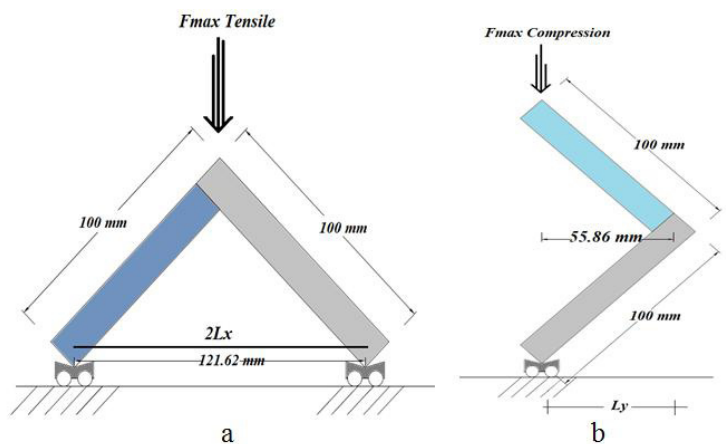

Fig. 3: a) Diagonal tensile test setup for corner "A", b) diagonal compression test setup for corner "B". Dimensions are in $\mathrm{mm}$.

\section{Experimental design and data analysis}

A total quantity of 120 samples were tested. Sixty of samples were used in compression and 60 in tension strength. Assortment of the specimens used in the test are depicted in Tab. 1.

Tab. 1: Assortment of tested specimens.

\begin{tabular}{|c|c|l|c|c|}
\hline Material type & Surface & Joint type & Compression (pcs) & Tension (pcs) \\
\hline \multirow{4}{*}{ Particleboard } & \multirow{4}{*}{ Non-overlaid } & PVAc glue & 5 & 5 \\
\cline { 3 - 5 } & & Screw & 5 & 5 \\
\cline { 3 - 5 } & \multirow{3}{*}{ Overlaid } & Dowel & 5 & 5 \\
\cline { 3 - 5 } & & PVAc glue & 5 & 5 \\
\cline { 3 - 5 } & & Screw & 5 & 5 \\
\cline { 3 - 5 } & Dowel & 5 & 5 \\
\hline \multirow{4}{*}{ Nandwich panel } & PVAc glue & 5 & 5 \\
\cline { 3 - 5 } & \multirow{3}{*}{ On-overlaid } & Screw & 5 & 5 \\
\cline { 3 - 5 } & & Dowel & 5 & 5 \\
\cline { 3 - 5 } & & PVAc glue & 5 & 5 \\
\cline { 3 - 5 } & & Screw & 5 & 5 \\
\cline { 3 - 5 } & & Dowel & 5 & 5 \\
\hline
\end{tabular}

Note: In all joint types such as screw and dowel joints corners were glued with PVAc.

Prior to any experiments, samples were dried at the climatization cabin following ASTM-D 1037 guidelines. Raw data was obtained through the compression and tensile strength tests. A Two-way MANOVA was conducted to assess the significant effect of three independent variables (material type, surface, joint type) on two dependent variables (compression and tension) using SPSS program, version 21.

\section{RESULTS AND DISCUSSION}

To assess the mechanical properties of various joint structures on furniture wood, two types of material (particleboard and sandwich board) was constructed. The mechanical and physical properties of the samples are given in Tab. 2 . 
Tab. 2: Mechanical and physical properties of samples.

\begin{tabular}{|c|l|c|c|c|}
\hline Material type & \multicolumn{1}{|c|}{ Surface } & Density $\left.\mathbf{( k g \cdot \mathbf { m } ^ { - 3 }}\right)$ & MOR $\mathbf{( M P a )}$ & MOE (MPa) \\
\hline \multirow{2}{*}{ Particleboard } & Non-overlaid & 710 & 13.23 & 1724.65 \\
\cline { 2 - 5 } & Overlaid & 730 & 13.54 & 1788.51 \\
\hline \multirow{2}{*}{ Sandwich panel } & Non-overlaid & 810 & 14.42 & 2123.27 \\
\cline { 2 - 5 } & Overlaid & 820 & 15.23 & 2234.33 \\
\hline
\end{tabular}

Looking at the compression moment values and tension moment values, non-overlaid particleboards have higher values than their overlaid counterparts. However, overlaid sandwich panels showed higher values than non-overlaid panels. Values of diagonal compression and tensile strength according to corner joint types are given in Tab. 3 .

Tab. 3: Diagonal compression and tensile strength moment values.

\begin{tabular}{|c|c|l|c|c|}
\hline Material type & Surface & Joint type & $\begin{array}{c}\text { Compression } \\
\text { moment (N.m) }\end{array}$ & $\begin{array}{c}\text { Tension } \\
\text { moment (N.m) }\end{array}$ \\
\hline \multirow{4}{*}{ Particleboard } & \multirow{4}{*}{ Non-overlaid } & PVAc glue & 10.32 & 17.26 \\
\cline { 3 - 5 } & & Screw & 17.04 & 20.54 \\
\cline { 3 - 5 } & \multirow{3}{*}{ Overlaid } & Dowel & 24.14 & 35.66 \\
\cline { 3 - 5 } & & PVAc glue & 3.07 & 5.98 \\
\cline { 3 - 5 } & & Screw & 12.60 & 21.07 \\
\cline { 3 - 5 } & Dowel & 10.32 & 19.10 \\
\hline \multirow{4}{*}{ Sandwich panel } & Non-overlaid & PVAc glue & 2.61 & 6.26 \\
\cline { 3 - 5 } & & Screw & 10.34 & 18.49 \\
\cline { 3 - 5 } & \multirow{3}{*}{ Overlaid } & Dowel & 10.68 & 25.86 \\
\cline { 3 - 5 } & & PVAc glue & 6.80 & 9.34 \\
\cline { 3 - 5 } & & Screw & 13.34 & 22.19 \\
\cline { 3 - 5 } & Dowel & 11.06 & 17.71 \\
\hline
\end{tabular}

Note: In all joint types such as screw and dowel joints corners were glued with PVAc.

\section{Multivariate analysis of variance on compression strength moment values}

Based on the statistical analysis, it was determined that there is a significant effect in diagonal compression strength moment values $(\mathrm{N} \cdot \mathrm{m})$ of non-overlaid particleboard and sandwich panels samples (if there is a statistical significant relation then the $\mathrm{F}$ statistic and its $\mathrm{p}$-value should be reported). Overall, screwed and dowel samples of overlaid particleboards have equal diagonal compression strength moment values $(\mathrm{N} \cdot \mathrm{m})$. With respect to overlaid sandwich panel samples, plain PVAc glued edge, dowel-PVAc samples, and screw PVAc samples have diagonal compression strength moment values of $9.34 \mathrm{~N} \cdot \mathrm{m}, 17.71 \mathrm{~N} \cdot \mathrm{m}$, and $22.19 \mathrm{~N} \cdot \mathrm{m}$, respectively. Screwed corner joint values when replaced with plain PVAc glue adhesive line, their value decreased from $22.19 \mathrm{~N} \cdot \mathrm{m}$ to $18.49 \mathrm{~N} \cdot \mathrm{m}$. Overall diagonal compression strength moment values (N.m) of the non-overlaid samples were substantially higher at dowel joint corners. Non-overlaid corner samples had a higher diagonal compression strength moment values in particleboard and sandwich panels $12.60 \mathrm{~N} \cdot \mathrm{m}$ and $13.34 \mathrm{~N} \cdot \mathrm{m}$, respectively (Fig. 4, 5). 


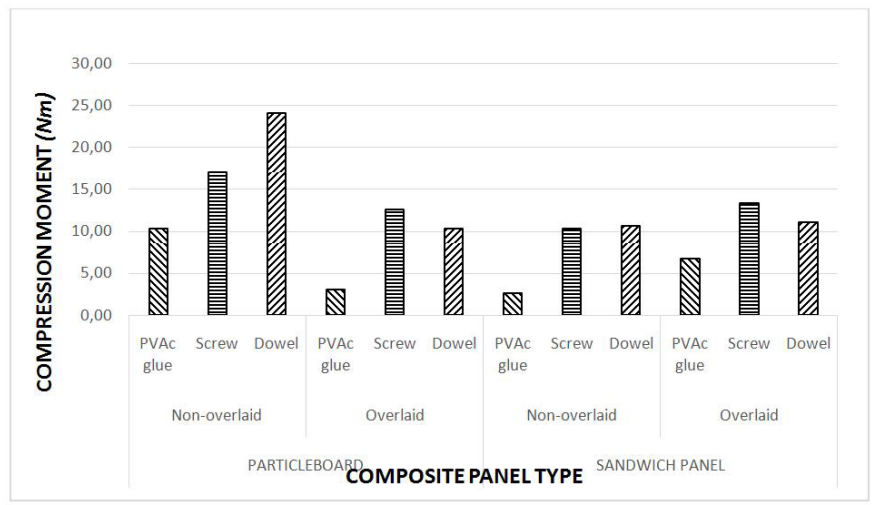

Fig. 4. Compression strength moment values $(N \cdot m)$ in different composite panels.

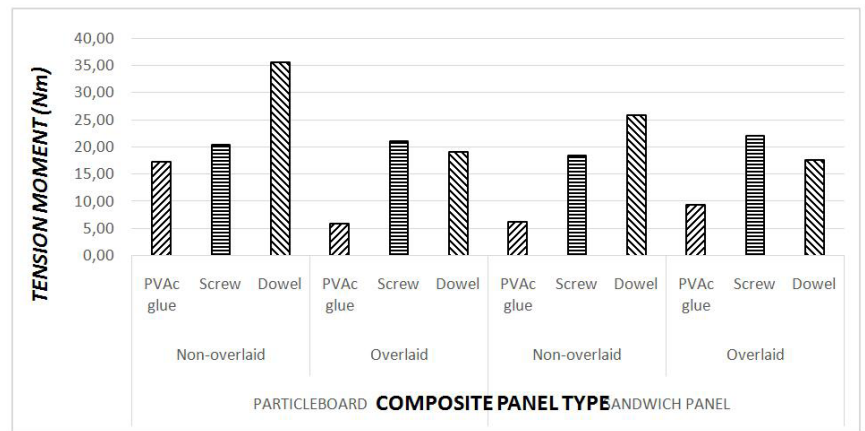

Fig. 5. Tension strength moment values $(N \cdot m)$ in different composite panels.

There was a statistically significant interaction effect between panel type and corner joint type on the compression strength moment variable with a $95 \%$ confidence level, $\mathrm{F}(6,48)=13.56$.

Tab. 4: Variance analysis according to interactions, units (-).

\begin{tabular}{|l|c|c|c|c|c|}
\hline \multicolumn{1}{|c|}{ Variance } & $\begin{array}{c}\text { Degrees of } \\
\text { freedom }\end{array}$ & Sum of square & Mean square & F value & P $<\mathbf{0 . 0 5 ~ S i g . ~}$ \\
\hline Panel type* & 3 & 804.124 & 268.041 & 116.315 & 0.0000 \\
\hline Corner joint type** & 2 & 856.078 & 428.039 & 185.744 & 0.0000 \\
\hline Panel x Corner & 6 & 187.509 & 31.252 & 13.561 & 0.0000 \\
\hline Error & 48 & 110.614 & 2.304 & & \\
\hline
\end{tabular}

* non-overlaid eastern redcedar PB, overlaid eastern red cedar, non-overlaid and overlaid sandwich panel.

** plain PVAc glued, PVAc and screw and PVAc and dowel.

The Duncan test results related to the homogeneous subsets according to the values determined in this work. Homogeneity group values-A of $17.16 \mathrm{~N} \cdot \mathrm{m}$ and $13.32 \mathrm{~N} \cdot \mathrm{m}$ and $14.05 \mathrm{~N} \cdot \mathrm{m}$ were determined for panel types and corner joint types, respectively (Tab. 5). 
Tab. 5: Comparative test results for compression strength moment values (N.m) and homogeneity groups.

\begin{tabular}{|c|l|c|c|c|}
\hline Parameters & \multicolumn{1}{|c|}{ Surface } & HG*A & HG*B & HG*C \\
\hline \multirow{5}{*}{ Panel type } & Non-overlaid particleboard $(\mathrm{N} \cdot \mathrm{m})$ & 17.16 & & \\
\cline { 2 - 5 } & Overlaid particleboard $(\mathrm{N} \cdot \mathrm{m})$ & & & 8.66 \\
\cline { 2 - 5 } & Non-overlaid sandwich panel $(\mathrm{N} \cdot \mathrm{m})$ & & & 7.87 \\
\cline { 2 - 5 } Joint type & Overlaid sandwich panel $(\mathrm{N} \cdot \mathrm{m})$ & & 10.39 & \\
\hline \multirow{3}{*}{} & PVAc glued $(\mathrm{N} \cdot \mathrm{m})$ & & 5.70 & \\
\cline { 2 - 5 } & PVAc and screw $(\mathrm{N} \cdot \mathrm{m})$ & 13.32 & & \\
\cline { 2 - 5 } & PVAc and dowel $(\mathrm{N} \cdot \mathrm{m})$ & 14.05 & & \\
\hline
\end{tabular}

\section{Multivariate analysis of variance on tensile strength moment values}

According to the multivariate analysis of variance, tensile strength values were affected by corner joint interactions. The effectiveness of the tensile strength moment on corner joint types of the samples, are displayed in Tab. 6. Based on statistical analysis, significant differences were observed between panel type and corner joint type 95\% confidence level. Corner joint types was found to be effective with different panel types $(\mathrm{p}<0.05)$ on compression strength moment values $(\mathrm{N} \cdot \mathrm{m})$.

Tab. 6: Variance analysis according to interactions, units (-).

\begin{tabular}{|l|c|c|c|c|c|}
\hline \multicolumn{1}{|c|}{ Variance } & $\begin{array}{c}\text { Degrees of } \\
\text { freedom }\end{array}$ & Sum of square & Mean square & F value & P $<\mathbf{0 . 0 5}$ Sig. \\
\hline Panel type* & 3 & 733.52 & 244.51 & 110.29 & 0.0000 \\
\hline Corner joint type** & 2 & 2497.02 & 1248.51 & 563.17 & 0.0000 \\
\hline Panel $x$ corner joint & 6 & 631.87 & 105.31 & 47.50 & 0.0000 \\
\hline Error & 48 & 106.41 & 2.21 & & \\
\hline
\end{tabular}

*non-overlaid eastern red cedar PB, overlaid eastern redcedar, non-overlaid and overlaid sandwich panel.

**aplain PVAc glued, PVAc and screw and PVAc and dowel.

Tab. 7 displays the Duncan test results related to the homogeneous subsets according to the values determined in this work. Homogeneity group values-A of 24.48 N.m and 25.08 N.m were determined for panel types and corner joint types, respectively.

Tab. 7: Comparative test results for tensile strength moment values (N.m) and homogeneity groups.

\begin{tabular}{|c|c|c|c|c|}
\hline Parameters & Surface & HG*A & HG*B & $\mathrm{HG}^{*} \mathrm{C}$ \\
\hline \multirow{4}{*}{ Panel type } & Non-overlaid particleboard $(\mathrm{N} \cdot \mathrm{m})$ & 24.48 & & \\
\hline & Overlaid particleboard (N.m) & & 16.04 & \\
\hline & Non-overlaid sandwich panel $(\mathrm{N} \cdot \mathrm{m})$ & & 16.86 & \\
\hline & Overlaid sandwich panel $(\mathrm{N} \cdot \mathrm{m})$ & & 16.41 & \\
\hline \multirow{3}{*}{ Joint type } & PVAc glued $(\mathrm{N} \cdot \mathrm{m})$ & & & 9.71 \\
\hline & PVAc and screw $(\mathrm{N} \cdot \mathrm{m})$ & & 20.56 & \\
\hline & PVAc and dowel $(\mathrm{N} \cdot \mathrm{m})$ & 25.08 & & \\
\hline
\end{tabular}

Screwed corner joints at overlaid sandwich panels have a higher compression and tensile moment values compared to eastern redcedar particleboard panels. Results of this study are comparable to Kasal`s study, where MDF panels with glued-screwed corner joints were stronger 
than particleboard panels (Kasal 2008). Screwed corner joints at overlaid sandwich panels have a higher compression and tension moment values compared to eastern redcedar particleboard panels. However, non-overlaid panel corners with dowels are stronger than other corner joint types. This result is consistent with the study of bending moment capacity of $\mathrm{L}$ type furniture corner joints which was constructed with vine pruning residues (Ozen et al. 2014).

\section{CONCLUSIONS}

The aim of this study was to find out compression and tension moment values of particleboards and sandwiched panels which were made from eastern redcedar particles with a modified starch. Comparative test results for compression strength and tension strength values revealed that moment capacity of corner joint samples was significantly affected by composite type and fixer type (PVAc, screw, and dowel). The maximum compression and tension moment values were achieved from non-overlaid particleboards (24.14 N.m and $35.66 \mathrm{~N} . \mathrm{m})$ that were connected by dowels. This result can be explained that PVAc glue is easily penetrated in wood structures and that furniture made from eastern redcedar particleboards are stronger after the glue has been applied. On the other hand, minimum compression and tension moment values were obtained in the overlaid particleboard samples $(3,07$ N.m and 5,98 N.m) that were connected by only PVAc glue.

It is appropriate to conclude that furniture producers should avoid plain glued corner constructions during box type furniture construction. In summary, this research supports that corner joints in eastern redcedar composite panels that are bound with modified starch such as particleboard and sandwiched panels are comparable with standard particleboards made from urea-formaldehyde or melamine-formaldehyde binders.

\section{REFERENCES}

1. Altun, S., Burdurlu, E., K1lı̧, M., 2010: Effect of adhesive type on the bending moment capacity of miter frame corner joints. BioResources 5(3): 1473-1483.

2. Altinok, M., Taş, H.H., Çimen, M., 2009: Effects of combined usage of traditional glue joint methods in box construction on strength of furniture. Materials \& Design 30(8): 3313-3317.

3. Cinar, H., Atar, M., Ustundag, A., 2019: The impact of dovetail angle in single dovetail joints on diagonal compression strength of corner joints for box-type furniture. Forest Products Journal 69(2): 131-140.

4. Efe, H., Özen, E., Danac1, E., Kasal, A., Demirci, S., 2014: Effect of joint technique on moment capacity of L-type furniture corner joints for case furniture constructed. Kastamonu University Journal of Forestry 14(1): 15-23.

5. Efe, H., Imirzi, H.O., 2008: Moment capacity of corner joints for case furniture constructed with different joint techniques and board thickness. Politeknik Dergisi 11(1): 65-75.

6. Eckelman, C.A. 1979. Withdrawal strength of dowel joints: Effect of shear strength. Forest Products Journal 29(1): 48-52.

7. Eckelman, C.A., Rabiej, R., 1985: A comprehensive method of analysis of case furniture. Forest Products Journal 35(4): 62-68.

8. Erdil, Y.Z., Kasal, A., Eckelman, C.A., 2005: Bending moment capacity of rectangular mortise and tenon furniture joints. Forest Products Journal 55(12): 209-213. 
9. Imirzi, H.O., Ozkaya, K., Efe, H., 2016: Determination of the strength of L-type corner joints obtained from wood-based board materials using different joining techniques. Forest Products Journal 66(3): 214-224.

10. Jensen, J.L., Sasaki, T., Koizumi, A., 2002: Plywood frame corner joints with glued-in hardwood dowels. Journal of Wood Science 48(4): 289-294.

11. Kasal, A., 2008: Effect of the number of screws and screw size on moment capacity of furniture corner joints in case construction. Forest Products Journal 58(6): 36-44.

12. Kasal, A., Smardzewski, J., Kuşkun, T., Erdil, Y.Z., 2016: Numerical analyses of various sizes of mortise and tenon furniture joints. BioResources 11(3): 6836-6853.

13. Küçüktüvek, M., Kasal, A., Kuşkun, T., Erdil, Y.Z., 2017: Utilizing poppy husk based particleboards as an alternative material in case furniture construction. BioResources 12(1): 839-852.

14. Koreny, A., Simek, M., Eckelman, C.A., Haviarova, E., 2013: Mechanical properties of knock-down joints in honeycomb panels. BioResources 8(4): 4873-4882.

15. Ozen, E., Göktas, O., Kasal, A., Efe, H., Demirci, S., 2014: Bending moment capacity of $\mathrm{L}$-type furniture corner joints constructed of particleboard produced from vine pruning residues. Wood Research 59(2): 313-322.

16. Ozkaya, K., Burdurlu, E., Ilce, A.C., Ciritcioglu, H.H., 2010: Diagonal tensile strength of an oriented strand-board (OSB) frame with dovetail corner joint. BioResources 5(4): 2690-2701.

17. Prekrat, S., Jazbec, A., Pervan, S., 2004: Analysis of the bending moment of innovative corner joints during static testing. Wood Research 49(1): 21-32.

18. Podlena, M., Borůvka, V., 2016: Stiffness coefficients of mortise and tenon joints used on wooden window profiles. BioResources 11(2): 4677-4687.

19. Podlena, M., Böhm, M., Múčka, M., Bomba, J., 2017: Determination of the bending moment of a dowel and tenon joint on window profile IV 92 of a wooden window. BioResources 12(2): 4202-4213.

20. Rajak, Z.I., Eckelman, C.A., 1993: Edge and face withdrawal strength of large screws in particleboard and medium density fiberboard. Forest products journal 43(4): 25.

21. Smardzewski, J., 1993: Stability of cabinet furniture backing boards. Wood Science Technology 28: 35-44.

22. Smardzewski, J., 2002: Strength of profile- adhesive joints. Wood Science and Technology 36(2): 173-183.

23. Simek, M., Haviarova, E., Eckelman, C., 2010: The effect of end distance and number of ready-to-assemble furniture fasteners on bending moment resistance of corner joints. Wood and Fiber Science 42(1): 92-98.

24. Ulker, O., 2018: Surface roughness of composite panels as a quality control tool. Materials 11(3): 407.

25. Ulker, O., Burdurlu, E., 2016: Effect of glass wool and stone wool additives on some mechanical properties of wood composites. BioResources 11(3): 5974-5986.

26. Yerlikaya, N.Ç., Aktaş, A., 2012: Enhancement of load carrying capacity of corner joints in case type furniture. Materials \& Design 37: 393-401.

27. Yerlikaya, N. Ç., 2014: Investigation of optimum dowel spacing for corner joints, which are reinforced with glass-fiber fabric in case-type furniture. Wood research 59(1): 91-200.

28. Záborský, V., Borůvka, V., Ruman, D., Gaff, M. 2017a: Effects of geometric parameters of structural elements on joint stiffness. BioResources 12(1): 932-946. 
29. Záborský, V., Borůvka, V., Kašičková, V., Ruman, D., 2017b: Effect of wood species, adhesive type, and annual ring directions on the stiffness of rail to leg mortise and tenon furniture joints. BioResources 12(4): 7016-7031.

30. Zhang, J., Efe, H., Erdil, Y.Z., Kasal, A., Han, N., 2005: Moment resistance of multiscrew L-type corner joints. Forest Products Journal 55(10): 56-63.

\author{
Onur Ulker*, Mercan Haddad Derafshi \\ ${ }^{1}$ University OF KiRIKKALE \\ Department of Interior Architecture and Environmental Design \\ YAHŞIHAN \\ TURKEY \\ 2Indiana University of Pennsylvania \\ Department of Human Development Fashion and Interior Design \\ INDIANA \\ USA \\ *Corresponding author: ulker79o@hotmail.com
}


